\title{
Viral respiratory infections and air pollutants
}

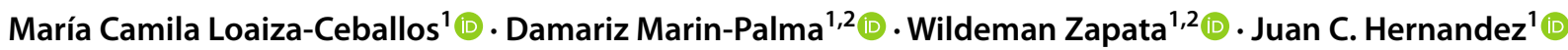

Received: 13 October 2020 / Accepted: 1 September 2021 / Published online: 15 September 2021

(c) The Author(s), under exclusive licence to Springer Nature B.V. 2021

\begin{abstract}
Air pollution is a public health issue of global importance and a risk factor for developing cardiorespiratory diseases. These contaminants induce reactive oxygen species (ROS) and increased pro-inflammatory cytokines such as IL-1 $\beta$, IL-6, and IL-8, triggering the inflammatory response that alters cell and tissue homeostasis and facilitates the development of diseases. The effects of air pollutants such as ozone, particulate matter (PM10, PM2.5, and PM0.1), and indoor air pollutants on respiratory health have been widely reported. For instance, epidemiological and experimental studies have shown associations between hospital admissions for individual diseases and increased air pollutant levels. This review describes the association and relationships between exposure to air pollutants and respiratory viral infections, especially those caused by the respiratory syncytial virus and influenza virus. The evidence suggests that exposure to air contaminants induces inflammatory states, modulates the immune system, and increases molecules' expression that favors respiratory viruses' pathogenesis and affects the respiratory system. However, the mechanisms underlying these interactions have not yet been fully elucidated, so it is necessary to develop new studies to obtain information that will allow health and policy decisions to be made for the adequate control of respiratory infections, especially in the most vulnerable population, during periods of maximum air pollution.
\end{abstract}

Keywords Air pollution $\cdot$ Viral infection $\cdot$ Particulate matter $\cdot$ Inflammation $\cdot$ Influenza $\cdot$ Ozone $\cdot$ Respiratory syncytial virus

\section{Introduction}

Industrial activities, the combustion of fossil products, and some natural processes generate chemical and biological substances that alter air quality. These pollutants can be classified as primary or secondary, depending on whether they are emitted directly into the atmosphere or they are the result of chemical reactions between the different atmospheric

Juan C. Hernandez

juankhernandez@gmail.com

María Camila Loaiza-Ceballos

mariac.loaiza@udea.edu.co

Damariz Marin-Palma

bleidy1122@gmail.com

Wildeman Zapata

Wildeman.zapatab@campusucc.edu.co

1 Infettare, Facultad de Medicina, Universidad Cooperativa de Colombia, Medellin, Colombia

2 Grupo Inmunovirologia, Facultad de Medicina, Universidad de Antioquia, UdeA, Medellin, Colombia pollutants present (Bernstein et al. 2004); furthermore, they can be classified into four categories according to their physio-chemical characteristics:

1. Gaseous pollutants: $\mathrm{SO}_{2}$ (sulfur dioxide), $\mathrm{NOx}$ (nitrogen oxides), ozone, volatile organic compounds, $\mathrm{CO}$ (carbon monoxides).

2. Persistent organic pollutants: polycyclic aromatic hydrocarbons, aldrin, dioxins, and furans.

3. Heavy metals: lead, mercury.

4. Particulate matter: PM10, PM2.5, and PM0.1.

These contaminants represent a risk to human health, increasing the incidence of cardiovascular and respiratory diseases and the mortality associated with these pathologies, becoming one of the most critical public health problems. In this sense, environmental pollution was responsible for 4.9 million deaths worldwide in 2017, related to COPD (chronic obstructive pulmonary disease), asthma, respiratory infections, lung cancer, and strokes (Stanaway et al. 2018; AriasPérez et al. 2020). 
It has been proposed that deleterious effects of pollutants are related to their ability to induce reactive oxygen species (ROS), which trigger oxidative stress and inflammation in the airways (Barraza-Villarreal et al. 2008). Eventually, these events can become systemic processes and promote prothrombotic mechanisms, alter heart rhythm and blood flow, and generate vascular dysfunction (Stieb et al. 2018). For example, it has been described that $\mathrm{SO}_{2}$ and PM2.5 can activate inflammatory pathways increasing fibrinogen and IL-8 (Chen et al. 2017); likewise, it has been reported that ozone can cause direct oxidation of the vasculature, thus favoring the development of hypertension, atherosclerosis, and heart failure (Bourdrel et al. 2017). On other hand, it has been proposed that environmental pollution is a risk factor for viral respiratory infections (Troeger et al. 2018), including as possible mechanisms inflammation, cell death, oxidative stress, and expression of viral receptors, among others, which will be addressed later.

\section{Respiratory diseases and air pollution}

Exposure to air pollutants has been linked to respiratory diseases such as asthma, COPD, and lung cancer, mainly in children and older adults. In China, a decrease in lung function and increased incidence of children with allergic rhinitis, related to pollutants exposure, were reported. The authors also reported a slight increase in other respiratory diseases such as recurrent infections, pneumonia, asthma, tracheitis, and bronchitis (Chen et al. 2019). Besides, He et al. (He et al. 2019) found that increased exposure to NOx in the womb, infancy, and childhood is associated with decreased lung function and wheezing, characteristic symptoms of COPD.

The acute effects of air pollution in people with COPD have been previously described. For example, in Spain, high concentrations of $\mathrm{CO}, \mathrm{NO}_{2}, \mathrm{O}_{3}$, and PM10 were reported to be significantly associated with the number of hospitalizations and mortality due to exacerbation of COPD, demonstrating the role of air pollutants in the development and clinical outcome of COPD (Miguel-Díez et al. 2019). In this sense, it has been proposed that short-term exposure to contaminants induces epigenetic modifications, inflammatory processes, and production of ROS, which can affect the function of the respiratory tract, alter the immune response, and activate different signaling pathways, favoring the exacerbation of COPD, and increased susceptibility to other pathologies such as cancer (Lichtenfels, et al. 2018; Eze et al. 2020).

In this sense, an epidemiological association between lung cancer mortality and exposure to air pollutants has been observed (Pope et al. 2002). Also, the relationship between exposure to air pollutants (PM10, $\mathrm{SO}_{2}$, and $\mathrm{NO}_{2}$ ) and hospital admissions for respiratory diseases has been explored, reporting significant increases for each $10 \mu \mathrm{g} / \mathrm{m}^{3}$ of the pollutants, with the elderly and women being the most vulnerable (Tao et al. 2014). Additionally, children under 5 years of age showed a higher number of hospital admissions for respiratory diseases associated with increases in environmental levels of $\mathrm{O}_{3}, \mathrm{NO}_{2}$, and PM10 (Gouveia and Fletcher 2000).

\section{Impact of airborne contaminants on respiratory viral infections}

Acute viral infections are the most common diseases globally, with children under 5 years of age being the most susceptible (Arbefeville and Ferrieri 2017). These infections are caused by various etiological agents, with high frequency, for viruses such as human Orthopneumovirus (formerly known as a respiratory syncytial virus-RSV), influenza virus (A, B, and C), and human rhinovirus, which can cause clinical conditions ranging from mild infections to laryngitis, bronchiolitis, episodes of wheezing, pneumonia, asthma attacks, and pharyngotonsillitis (Valero et al. 2009). According to epidemiological data, lower respiratory tract infections were the sixth leading cause of death globally, and the first in children under 5 years of age. Among the most common etiologies, RSV was the second leading etiology, to which 76,612 deaths were attributed (in children under 5 years of age, it was the cause of $54 \%$ of fatalities); while the influenza virus was associated with non-fatal episodes and was positioned as the fourth etiological agent (Troeger et al. 2018). It was also established that the main associated risk factors were malnutrition, air pollution, and exposure to environmental particles; the latter can act in a more harmful way and acts in conjunction with certain viruses, thus conditioning the development of infectious diseases (Wang et al. 2021).

Correlations between infection by different viruses and air pollutants have been reported. It has been described that the increase in contaminants such as benzene is positively correlated with the detection of rhinovirus in the nasal passages, suggesting that air quality affects the viral infectivity (Rodrigues et al. 2019). According to this, in vitro assays have described a synergism between the exposure to $\mathrm{NO}_{2}$ and the rhinovirus infection in nasal and bronchial epithelial cells. This phenomenon is associated with increased expression of pro-inflammatory cytokines such as IL-8, and the intracellular adhesion molecule 1 (ICAM-1), which acts as the primary receptor of the virus (Spannhake et al. 2002). Other contaminants, such as biomass smoke derived from wood burning, can modulate the inflammation produced by rhinovirus by inducing pro-inflammatory mediators production (i.e., IL-6 and IL-8) (Capistrano et al. 2016). Similarly, sand dust can induce the expression of IFN $\gamma$, IL-1 $\beta$, IL-6, 
and IL-8 in nasal epithelial cells and promote rhinovirus replication (Yeo et al. 2010), besides stimulating the expression of mucins (MUC4 and MUC5B), necessary for the maintenance of mucosal defense (Kim et al. 2011).

RSV infection is also influenced by air pollution. It has been described a positive correlation between the RSV incidence and the levels of air pollutants such as benzene, NOx, $\mathrm{SO}_{2}$, PM10, and PM2.5 (Nenna et al. 2017). In vitro assays have demonstrated that RSV-infected dendritic cells exposed to NO have a positive effect on viral replication by decreasing the function of the nitric oxide synthase, which facilitates the viral spread (Hobson and Everard 2008).

Although the SARS-CoV-2 virus was recently discovered, it has been suggested that airborne contaminants, and especially PM2.5, $\mathrm{CO}$, and $\mathrm{NO}_{2}$, may be implicated in the incidence and severity of clinical manifestations of COVID-19 (Conticini et al. 2020; Pansini and Davide 2020; Copat et al. 2020). In the USA, long-term exposure to PM2.5, of only $1 \mu \mathrm{g} / \mathrm{m}^{3}$, has been found to cause an $8 \%$ increase in the mortality rate of COVID-19, demonstrating the importance of environmental pollution control measures to protect human health during the COVID-19 pandemic (Wu et al. 2020). Additionally, a study in northern Italy examined the correlation between SARS-CoV-2 mortality and air pollution, providing evidence that people living in an area with high levels of contaminants are more likely to develop respiratory disease, including that associated with viral infections such as SARS-CoV-2 (Conticini et al. 2020). These associations can be explained by the presence, in the regulatory region of the ACE-2 (angiotensin-converting enzyme 2) gene, of consensus motifs for the transcription factor AhR, which is stimulated by molecules present in the PM. Therefore, prolonged exposure to $\mathrm{PM}$ causes overexpression of ACE-2 receptor in the human airways and favors SARS-CoV-2 infectivity (Borro et al. 2020).

The effects of pollutants such as PM10, PM2.5, $\mathrm{SO}_{2}$, and $\mathrm{NO}_{2}$, on respiratory viral infections, are mainly mediated by the increase of pro-inflammatory cytokines, the alteration of the immune response, and, in the case of rhinovirus, the rise in the expression of its receptor (ICAM-1). Together, these mechanisms facilitate viral pathogenesis, as evidenced by the increase of hospitalizations and incidence of viral infections.

\section{Particulate matter}

Environmental PM is a mixture of suspended particles, which, according to their aerodynamic diameter, can enter several anatomical sites in the airways and trigger different effects (Fig. 1). It is classified into three categories: PM10 or coarse, with a diameter less than $10 \mu \mathrm{m}, \mathrm{PM} 2.5$

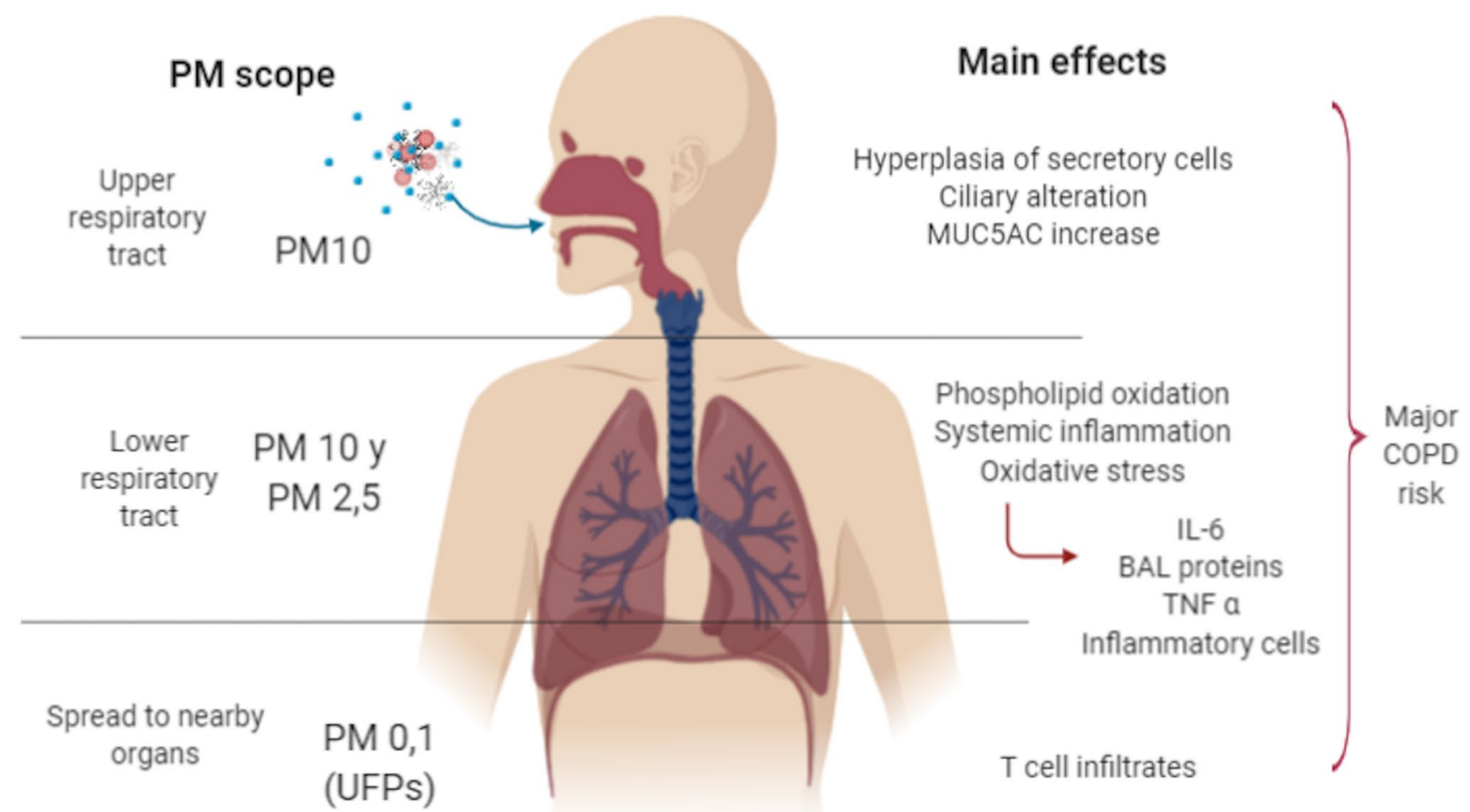

Fig. 1 Main effects and anatomical reach of particulate matter. Depending on the aerodynamic diameter $(<0.1 \mu \mathrm{m}, 2.5 \mu \mathrm{m}$, or $10 \mu \mathrm{m}), \mathrm{PM}$ has the capacity to enter different anatomical sites of the respiratory tract, where it can remain or spread to other organs and tissues, causing diverse effects on them, and increasing susceptibility to human pathologies, including COPD 
with a diameter less than $2.5 \mu \mathrm{m}$, and PM0.1 or ultrafine with a diameter less than $0.1 \mu \mathrm{m}$ (Bernstein et al. 2004). PM formation occurs primarily through a combination of particles derived from fossil fuel combustion, road traffic, and emissions from power and agricultural plants. The acute effects of this material are mainly based on inflammation and cytotoxicity. In contrast, chronic effects have been associated with DNA damage, destruction of the lung parenchyma, lung fibrosis, or granuloma formation (Nemmar et al. 2013). Additionally, it has been associated with acute lower respiratory tract infections. This is because it can modulate the innate immune system of the respiratory tract through mechanisms such as inflammation mediated by alveolar macrophages (with decreased phagocytic and microbicidal capacity), recruitment of neutrophils, disruption of barrier defenses, and upregulation of receptors and molecules involved in the invasion of pathogens (Lee et al. 2015).

\section{PM10}

PM10 exposure has been associated with high oxidative potential related to ROS generation, cytotoxicity, inflammation, and DNA damage, resulting in neutrophil recruitment and altered endothelial permeability (Schilirò et al. 2010; Ghanbarian et al. 2019). In addition, PM modulates the innate immune system and several genes related to metabolic pathways (Mishra et al. 2020), which together make it more susceptible to attack by various pathogens and facilitate their infectivity and replication.

Studies in Italy found an association between PM10 exposure and increased risk of hospitalization for bronchiolitis caused by RSV in children under one year of age (Carungo et al. 2018). Accordingly, increased survival of RSV viral particles was reported when bound to PM10. Furthermore, when the mixture of PM10 and virus is in contact with epithelial cells, they increased the secretion of pro-inflammatory mediators such as IL- 6 and IL-8, compared with the same dose of virus alone (Cruz Sánchez et al. 2013) (Fig. 2), explaining the high rates of RSV hospitalizations in the presence of high levels of PM10.

It has been observed that PM10 can remain for long periods, in the respiratory tract, before being eliminated. This prolonged exposure of epithelial cells may contribute to the secretion of pro-inflammatory cytokines such as

INDOOR AIR POLLUTION

ULTRAFINE PARTICLES

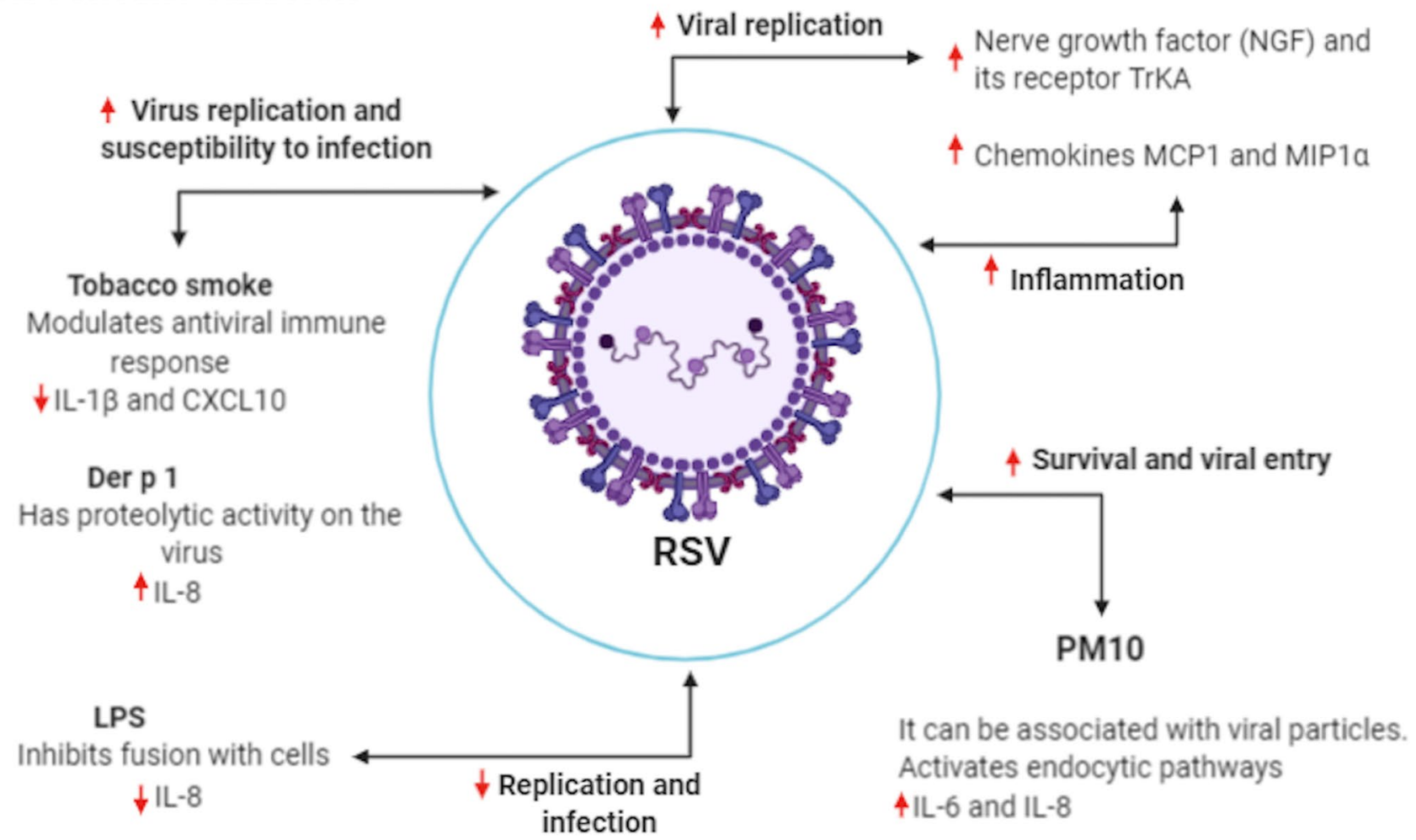

Fig. 2 Effects of different air pollutants on RSV. Different studies have evaluated the main effects caused by exposure to air pollutants such as ultrafine particles, PM10, and indoor air pollution on the cells and tissues of the respiratory system, obtaining as fundamental mech- anisms the alteration of the immune response, signaling pathways, and cytokine production, which has been observed to have a direct impact on RSV infection 
IL-1 $\beta$, in response to influenza A infection, in an NLRP3dependent mechanism. This suggests that exposure to high concentrations of PM10 may increase the immune response to subsequent viral infections, having implications on the development of respiratory disease (Hirota et al. 2015) (Fig. 3). It was also found that PM10 and temperature are associated with pediatric cases of infections by the influenza A virus. Both factors can synergize in children's respiratory tract, resulting in increased infection susceptibility by the influenza virus (Xu et al. 2013; Zhang et al. 2021).

\section{PM2.5}

PM2.5 can induce an aberrant cell cycle through the overexpression of microRNA155 (miR155). The miR155 induces epigenetic modulation of the SOCS1/STAT3 signaling pathway, contributing to the imbalance of pulmonary homeostasis, associated with inflammatory and oncogenic processes, which may contribute to the susceptibility to pathogens (Xiao et al. 2019).

Additionally, it has been observed in murine models that exposure to PM2.5 induces pathological changes such as recruitment and activation of inflammatory cells (mainly macrophages and neutrophils), secretion of pro-inflammatory factors (CNTF, IL-6, MCP-1, RAGE, MMP-8, TIMP-1, and chemokine thymic 1), production of free radicals (MDA, $\mathrm{H}_{2} \mathrm{O}_{2}$, and $\mathrm{NO}$ ), and destruction of extracellular matrix, evidenced by an increase of MMP-9 and elastase. Together, these factors led to the activation of the inflammatory response, resulting in damage of the alveolar-capillary barrier and increased vascular permeability. Thus, making the respiratory system more susceptible to deposited PM2.5 and exacerbating the pathogenesis of respiratory diseases (Yang et al. 2018). An epidemiological study showed a $5 \%$ increase in hospitalizations for respiratory infections in children, after a rise of $10 \mathrm{ug} / \mathrm{m}^{3}$ of PM2.5 in Chile, reflecting the synergism between PM and the presence of the virus in the environment (Matus and Oyarzún 2019).

The acute in vivo exposure to PM2.5 and subsequent infection with the influenza A virus increased the survival rate compared to mice infected in the absence of PM2.5, due to an increase in the antiviral mechanisms induced by PM. However, the prolonged exposure to PM2.5 causes a state of immune exhausting in the lung, characterized by a decrease in the secretion of IL- 6 and IFN- $\beta$, favoring the infection progression (Ma et al. 2017). Furthermore, PM2.5 induces ROS production, expression of adhesion molecules, such as ICAM-1 and VCAM-1, and activation

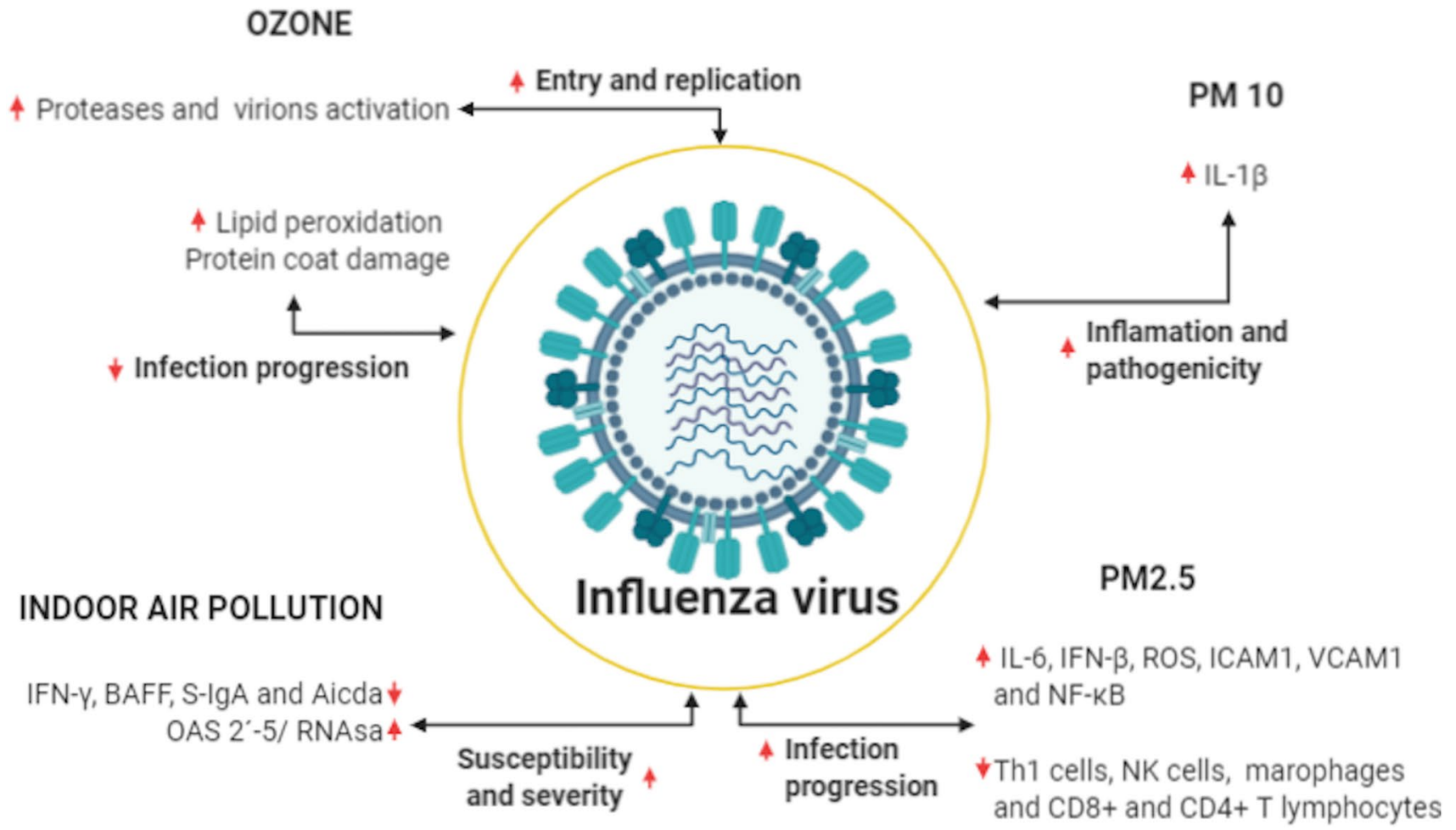

Fig. 3 Effects of different pollutants on influenza virus. It has been observed that air pollutants such as ozone, indoor air pollution, PM10, and PM2.5 can alter the immune response and production of different cytokines and other molecules in the cells and tissues of the respiratory system exposed, modifying their function and integrity, and can also alter the viral particle, thus directly affecting the infection of the influenza virus 
of NF- $\mathrm{kB}$ in endothelial cells (Rui et al. 2016), favoring the influenza virus infection (Nimmerjahn et al. 2004). Other studies have shown that newborn mice (with an immature immune system) exposed to PM2.5-associated free radicals have increased regulatory $\mathrm{T}$ cells and IL-10 following influenza A infection. This modulation of the immune response inhibits the activity of CD8 + and CD4 + T lymphocytes, essential for the elimination of the virus (Jaligama et al. 2017). This phenomenon, together with the pulmonary oxidative stress, increases the susceptibility and severity of influenza virus infection, decreasing the survival rate (Lee et al. 2014) (Fig. 3). This association has also been observed in epidemiological studies, showing an increase in disease incidence by the influenza virus associated with higher levels of PM2.5 (Liang et al. 2014; Lu et al. 2020).

Other studies have also found the relationship between PM2.5 levels and RSV disease. In Chile and Polonia, for example, it was reported that for each increase of $10 \mu \mathrm{g} /$ $\mathrm{m}^{3}$ of PM2.5, the number of hospitalizations for respiratory diseases caused by RSV increased between 2 and 5\% (Matus and Oyarzún 2019; Wrotek et al. 2021). Likewise, in the USA, an increase in bronchiolitis risk attributable to chronic exposure to vehicle traffic particles was found (Karr et al. 2009).

\section{PM0.1}

PM0.1 has a greater capacity to alter lung function, because of its small size, it can penetrate deeply and remain in the airways for long periods, having more significant inflammatory, oxidative, and cytotoxic potential, and causing changes in lung permeability (Renwick et al. 2004). It has been reported that dendritic cells exposed to PM0.1, showed increased expression of CD83 and CCR7, potentiating the proliferation of $\mathrm{CD} 8+\mathrm{T}$ lymphocytes and their production of IFN- $\gamma$, TNF- $\alpha$, IL-13, and granzymes. This enhanced cytotoxic response could be associated with pathological inflammation during concurrent infections, increasing airway damage (Pfeffer et al. 2018). Furthermore, it has been described that ultrafine particles trigger endocytosis and autophagy in respiratory epithelial cells, essential processes for PM-induced inflammation and mucus overproduction, related with the activation of NF- $\mathrm{KB}$ and AP-1 pathways, and subsequent production of IL-8, IL-6, and mucin 5AC (Chen et al. 2016).

Previous exposure of bronchial epithelial cells to environmental nanoparticles increases the susceptibility to RSV infection, with increased efficiency of viral replication. The underlying mechanisms involve the autophagy and apoptosis pathways, thus facilitating viral replication, and rapid spread of the infection (Chakraborty et al. 2017). Also, a synergistic effect between exposure to ultrafine carbon particles and RSV infection has been described in mice, in which a worsening of airway hyperreactivity, lung inflammation (i.e. infiltration of neutrophils and lymphocytes), and high production of chemokines (MCP-1 and MIP-1 $\alpha$ ) have been found (Lambert et al. 2003). The cells of the immune system attracted to the respiratory epithelium in addition to acting against infection can contribute to the inflammatory process and the development of lesions in the tissue. For instance, neutrophils releasing ROS and enzymes of their granules degrade components of the extracellular matrix and activate other inflammatory cells such as macrophages, which produce inflammatory mediators such as TNF- $\alpha$, IL- $1 \beta$, and IL- 6 , among others (Fig. 2).

\section{Ozone}

Ozone is a gas produced in the environment by oxidation-reduction reactions between NOx precursors such as nitric oxide $(\mathrm{NO})$ and nitrogen dioxide $\left(\mathrm{NO}_{2}\right)$, volatile organic compounds (VOCs), and primary hydrocarbons containing -OH radicals (Holland and Turekian 2005). Acute exposure to this gas alters lung and bronchial tissue, producing lesions with desquamation and hypercellularity, loss of cilia, necrosis, and bronchiolar interstitial inflammation. These effects are mediated by the modulation of pathways involved in tissue repair and regeneration, the production of eicosanoids and reactive nitrogen species, and oxidative damage, among others (Sunil et al. 2013). In addition, ozone exposure induces the expression of inflammatory markers, including IL-6, CXCL1, CCL2, and myeloperoxidase (Holze et al. 2018).

Acute exposure to ozone increases the susceptibility to influenza A virus infection by several mechanisms. It has been reported that oxidative stress induced by ozone alters cellular membranes and increases the susceptibility to proteases secreted by the respiratory nasal epithelium, thus activating the influenza A virus, and favoring its infectivity (Kesic et al. 2012) (Fig. 3). Epidemiological studies have shown associations between ozone concentrations and influenza cases. In Hong Kong, it was observed that for every $10 \mu \mathrm{g} / \mathrm{m}^{3}$ increase in ozone concentration, mortality and hospitalization due to influenza infection increase (Wong et al. 2009). Similar results were reported in China where it was also related to cold seasons (Meng et al. 2021). However, conflicting results have been reported (Ali et al. 2018). This could be explained by the antiviral potential attributed to ozone against several viruses such as influenza, rhinovirus, adenovirus, poliovirus, and enterovirus 71 , causing genome damage (Ji et al. 2019) and affecting the production of viral progeny by modulating the immune response (Lin et al. 2007). 


\section{Indoor air pollutants}

Indoor air pollutants result from activities such as smoking, the use of cleaning and personal care products, and the use of household appliances which can release compounds such as $\mathrm{CO}$, nitrogen oxides, metals, and gases that, when added to outdoor air pollutants, are highly harmful to human health (Carazo Fernández et al. 2013). Deteriorating indoor air quality has a significant impact on respiratory health and has been associated with an increased risk of respiratory diseases such as COPD, pneumonia, asthma, and infections (Gordon et al. 2014). In this regard, the relationship between acute exposure to domestic pollution caused by solid fuels in poorly ventilated homes and respiratory diseases has been reported (Nsoh et al. 2019).

Foster et al. (Foster et al. 2003) reported the effect of two biologically active indoor air contaminants on RSV replication. For this, respiratory epithelial cells were exposed to lipopolysaccharide (LPS), or Der p 1, an allergen of house dust mites. The results showed that RSV infection and IL-8 production decreased in a dose-dependent manner with LPS, in contrast with Der p 1, which increased viral progeny production and IL-8 expression (Foster et al. 2003). These results are explained by the ability of LPS to interact with the cellular receptors involved in RSV infection, inhibiting virus-cell adhesion and thus decreasing virus infectivity, and the production of IL-8 (Hallak et al. 2000). In the same way, Der p 1, due to its proteolytic activity, has been attributed the capacity of splitting cellular receptors such as CD25, which causes a decrease in the proliferation of $\mathrm{T}$ lymphocytes, the production of IFN $-\gamma$, and increase of IL-4, favoring the synthesis of IgE (Ghaemmaghami et al. 2001). Besides, it polarizes the immune response towards the Th2 profile (Comoy et al. 1998), modulating the immune response thus favoring viral replication.

Different epidemiological studies have evaluated the relationship between exposure to tobacco smoke and RSV infection. It has been found that passive exposure to these particles constitutes a risk factor for diseases by RSV, mainly in infants under 5 years old, which is evidenced by an increase in hospital admissions due to complications derived from the infection by this virus (Maedel et al. 2018). Among the mechanisms involved are cigarette smoke's ability to induce necrosis during RSV infection facilitates viral replication in the respiratory tract (Groskreutz et al. 2009). Additionally, RSV can negatively modulate the antiviral response mediated by interferon, as well as diminish the production of cytokines and chemokines, such as IL-1 $\beta$, CXCL10 (Castro et al. 2011), and leukemia inhibitory factor (LIF), which has an important role in the prevention of lung injury (Poon et al. 2019), thus increasing the susceptibility to infection, particularly in those individuals exposed to cigarette smoke in a chronic way (Modestou et al. 2010) (Fig. 2).
Analysis of air from daycare centers, health centers, and airplanes showed that the influenza $\mathrm{A}$ virus has the capacity to associate with PM, which enables its dissemination and entry to the body (Yang et al. 2011). On the other hand, it was demonstrated that the exposure to cigarette smoke before the infection by the influenza A virus decreases the production of IFN-g by lung $\mathrm{T}$ lymphocytes in a process mediated by the phosphorylation of transcription factors such as CREB, ATF-2, and c-Jun, leading to reduced immunity and increased symptoms caused by the influenza virus (Feng et al. 2011). Additionally, it has been reported that the immune response triggered by the influenza A virus in the presence of cigarette smoke activates the oligoadenylate synthase $2^{\prime}-5 /$ RNAse L system in the lungs, triggering an exaggerated antiviral and inflammatory immune response and favoring the development of other pathologies such as COPD (Zhou et al. 2013). Finally, chronic exposure to cigarette smoke, before infection by the influenza virus, leads to an oxidative inhibition of BAFF (B cell-activating factor belonging to the TNF family) and consequently of the secretory immunoglobulin $\mathrm{A}$ in the lung, in addition to a decrease of the AICDA gene, which contributes to a higher incidence and severity of viral infections in smokers (Wang et al. 2015).

\section{Conclusion}

In recent decades, worldwide concern has increased about the decrease in air quality, and its negative impact on human health. Among the observed effects, experimental studies show that exposure to different air pollutants favors the pathogenesis of viral respiratory infections, through common mechanisms. In the first steps, these pollutants have the ability to induce ROS production, leading to an oxidative state, the activation of the transcription factors NF-kB and AP-1, and the subsequent production of cytokines such as IL-1 $\beta$, IL-6, IL-8, IL-13, and TNF- $\alpha$, among others. Furthermore, the air pollutants can affect the cellular cycle, by inducing cytotoxicity and genotoxicity. Together, these mechanisms exacerbate the inflammatory state, and the hyperreactivity of the respiratory tract, altering the respiratory tract's homeostasis and making it more susceptible to viral infections, including influenza and RSV. Besides, the epidemiological evidence has shown that the increase in clinical manifestations, hospitalizations, and emergency room visits related to these infections are associated with high air pollution periods. However, the mechanisms involved and the comprehensive understanding of air pollutants' consequences on the clinical course, pathogenesis, or prognosis of specific viral infections still require research. 
Author contribution Conceptualization: JCH.

Writing-Original Draft: MCL, DMP, JCH.

Writing-Review \& Editing: DMP, WZ, JCH.

Project formulation: MCL and JCH. Manuscript preparation: MCL, LDM, WZ, and JCH. All authors approved the final version of the manuscript.

Funding Universidad Cooperativa de Colombia (INV 2194), Minciencias (Grant 141580763047).

\section{Declarations}

Conflict of interest The authors declare no conflict of interest.

\section{References}

Bernstein JA, Alexis N, Barnes C, Bernstein IL, Nel A, Peden D et al (2004) Health effects of air pollution. J Allergy Clin Immunol 114(5):1116-1123. https://doi.org/10.1016/j.jaci.2004.08.030

Stanaway JD, Afshin A, Gakidou E, Lim SS, Abate D, Abate KH et al (2018) Global, regional, and national comparative risk assessment of 84 behavioral, environmental and occupational, and metabolic risks or clusters of risks for 195 countries and territories, 1990-2017: a systematic analysis for the Global Burden of Disease study 2017. Lancet 392(10159):1923-1994. https://doi.org/ $10.1016 / \mathrm{S} 01406736(18) 32225-6$

Arias-Pérez RD, Taborda NA, Gómez DM, Narvaez JF, Porras J, Hernandez JC (2020) Inflammatory effects of particulate matter air pollution. Environ Sci Pollut Res 27:42390-42404. https://doi. org/10.1007/s11356-020-10574-w

Barraza-Villarreal A, Sunyer J, Hernandez-Cadena L, Escamilla-Nuñez MC, Sienra-Monge JJ, Ramírez-Aguilar M et al (2008) Air pollution, airway inflammation, and lung function in a cohort study of Mexico city schoolchildren. Environ Health Perspect 116(6):832838. https://doi.org/10.1289/ehp.10926

Stieb DM, Shutt R, Kauri LM, Roth G, Szyszkowicz M, Dobbin NA et al (2018) Cardiorespiratory effects of air pollution in a panel study of winter outdoor physical activity in older adults. J Occup Environ Med 60(8):673-682. https://doi.org/10.1097/JOM.00000 00000001334

Chen S-Y, Chan C-C, Su T-C (2017) Particulate and gaseous pollutants on inflammation, thrombosis, and autonomic imbalance in subjects at risk for cardiovascular disease. Environ Pollut 223:403408. https://doi.org/10.1016/j.envpol.2017.01.037

Bourdrel T, Bind M-A, Béjot Y, Morel O, Argacha J-F (2017) Cardiovascular effects of air pollution. Arch Cardiovasc Dis 110(11):634-642. https://doi.org/10.1016/j.acvd.2017.05.003

Troeger C, Blacker B, Khalil IA, Rao PC, Cao J, Zimsen SRM et al (2018) Estimates of the global, regional, and national morbidity, mortality, and aetiologies of lower respiratory infections in 195 countries, 1990-2016: a systematic analysis for the Global Burden of Disease study 2016. Lancet Infect Dis 18(11):1191-1210. https://doi.org/10.1016/j.acvd.2017.05.003

Chen Z, Cui L, Cui X, Li X, Yu K, Yue K et al (2019) The association between high ambient air pollution exposure and respiratory health of young children: a cross-sectional study in Jinan. China Sci Total Environ 656:740-749. https://doi.org/10.1016/j.scito tenv.2018.11.368

He B, Huang JV, Kwok MK, Au Yeung SL, Hui LL, Li AM et al (2019) The association of early-life exposure to air pollution with lung function at $\sim 17.5$ years in the "Children of 1997"
Hong Kong Chinese birth cohort. Environ Int. 123:444-450. https://doi.org/10.1016/j.envint.2018.11.073

de Miguel-Díez J, Hernández-Vázquez J, López-de-Andrés A, Álvaro-Meca A, Hernández-Barrera V, Jiménez-García R (2019) Analysis of environmental risk factors for chronic obstructive pulmonary disease exacerbation: a case-crossover study (2004-2013). PLoS ONE 14(5):e0217143. https://doi.org/ 10.1371/journal.pone. 0217143

de Lichtenfels AJFC, van der Plaat DA, de Jong K, van Diemen CC, Postma DS, Nedeljkovic I et al (2018) Long-term air pollution exposure, genome-wide DNA methylation and lung function in the lifelines cohort study. Environ Health Perspect 126(2):027004. https://doi.org/10.1289/EHP2045

Eze IC, Jeong A, Schaffner E, Rezwan FI, Ghantous A, Foraster $M$ et al (2020) Genome-wide DNA methylation in peripherial blood and lonh-term exposure to source-specific transportation noise and air pollution: The SAPALDIA study. Environ Health Perspect 128(6):067003. https://doi.org/10.1289/EHP6174

Pope CA, Burnett RT, Thun MJ, Calle EE, Krewski D, Ito K et al (2002) Lung cancer, cardiopulmonary mortality, and long-term exposure to fine particulate air pollution. JAMA 287(9):11321141. https://doi.org/10.1001/jama.287.9.1132

Tao Y, Wangd S, Mib S, Xiea X, Zhou S (2014) Air pollution and hospital admissions for respiratory diseases in Lanzhou. China Environ Pollut 185:196-201. https://doi.org/10.1016/j.envpol. 2013.10.035

Gouveia N, Fletcher T (2000) Respiratory diseases in children and outdoor air pollution in São Paulo, Brazil: a time series analysis. Occup Environ Med 57(7):477-483. https://doi.org/10.1136/ oem.57.7.477

Arbefeville S, Ferrieri P (2017) Epidemiologic analysis of respiratory viral infections mainly in hospitalized children and adults in a Midwest University medical center after the implementation of a 14-virus multiplex nucleic acid amplification test. Am J Clin Pathol 147(1):43-49. https://doi.org/10.1093/ajcp/aqw185

Valero N, Larreal Y, Arocha F, Gotera J, Mavarez A, Bermudez $\mathrm{J}$ et al (2009) Etiología viral de las infecciones respiratorias agudas. Invest Clin 50(3):359-368

Wang ZB, Ren L, Lu QB, Zhang XA, Miao D, Hu YY et al (2021) The impact of weather and air pollution on viral infection and disease outcome among pediatric pneumonia patients in Chongqing, China, from 2009 to 2018: a prospective observational study. Clin Infect Dis 73(2):e513-e522. https://doi.org/10.1093/ $\mathrm{cid} / \mathrm{ciaa} 997$

Rodrigues AF, Santos AM, Ferreira AM, Marino R, Barreira ME, Cabeda JM (2019) Year-long rhinovirus infection is influenced by atmospheric conditions, outdoor air virus presence, and immune system-related genetic polymorphisms. Food Environ Virol 11(4):340-349. https://doi.org/10.1007/s12560-019-09397-x

Spannhake EW, Reddy SPM, Jacoby DB, Yu X-Y, Saatian B, Tian J (2002) Synergism between rhinovirus infection and oxidant pollutant exposure enhances airway epithelial cell cytokine production. Environ Health Perspect 110(7):665-670. https://doi.org/10. 1289/ehp.02110665

Capistrano SJ, Zakarya R, Chen H, Oliver BG (2016) Biomass smoke exposure enhances rhinovirus-induced inflammation in primary lung Fibroblasts. Int J Mol Sci 17(9):1403. https://doi.org/10. 3390/ijms 17091403

Yeo N-K, Hwang Y-J, Kim S-T, Kwon HJ, Jang YJ (2010) Asian sand dust enhances rhinovirus-induced cytokine secretion and viral replication in human nasal epithelial cells. Toxicol Inhal 22(12):1038-1045. https://doi.org/10.3109/08958378.2010. 516282

Kim S-T, Ye M-K, Shin S-H (2011) Effects of Asian Sand Dust on Mucin Gene Expression and Activation of Nasal Polyp Epithelial 
Cells. Am J Rhinol Allergy 25(5):303-306. https://doi.org/10. 2500/ajra.2011.25.3627

Nenna R, Evangelisti M, Frassanito A, Scagnolari C, Pierangeli A, Antonelli G et al (2017) Respiratory syncytial virus bronchiolitis, weather conditions and air pollution in an Italian urban area: an observational study. Environ Res 158:188-193. https://doi.org/10. 1016/j.envres.2017.06.014

Hobson L, Everard ML (2008) The persistent respiratory syncytial virus in human dendritic cells and the influence of nitric oxide. Clin Exp Immunol 151(2):359-366. https://doi.org/10.1111/j. 1365-2249.2007.03560.x

Conticini E, Frediani B, Caro D (2020) Can atmospheric pollution be considered a co-factor in extremely high levels of SARS-CoV-2 lethality in Northern Italy? Environ Pollut 261:114465. https:// doi.org/10.1016/j.envpol.2020.114465

Pansini R, Davide F (2020) COVID-19 higher mortality in Chinese regions with chronic exposure to lower air quality. Front Public Health 8:597753. https://doi.org/10.3389/fpubh.2020.597753

Copat C, Cristaldi A, Fiore M, Grassi A, Zuccarello P, Signorelli SS et al (2020) The role of air pollution (PM and $\mathrm{NO}_{2}$ in COVID19 spread and lethality: a systematic review. Environ Res 191:110129. https://doi.org/10.1016/j.envres.2020.110129

Wu X, Nethery RC, Sabath BM, Braun D, Dominici F. Exposure to air pollution and COVID-19 mortality in the United States: a nationwide cross-sectional study. medRxiv. 2020; 2020.04.05.20054502. https://doi.org/10.1101/2020.04.05.20054502

Borro M, Di Girolamo P, Gentile G, De Luca O, Preissner R, Marcolongo A et al (2020) Evidence-based considerantions exploring relations between SARS-CoV-2 pandemic and air pollution: Involvement of PM2.5 mediated up-regulation of the viral receptor ACE-2. Int J Environ Res Public Health 17(15):5573. https:// doi.org/10.3390/ijerph17155573

Nemmar A, Holme JA, Rosas I, Schwarze PE, Alfaro-Moreno E. Recent advances in particulate matter and nanoparticle toxicology: a review of the in vivo and in vitro studies. Biomed Res Int 2013 2013. https://doi.org/10.1155/2013/279371

Lee A, Kinney P, Chillrud S, Jack D (2015) A systematic review of innate immunomodulatory effects of household air pollution secondary to the burning of biomass fuels. Ann Glob Health 81(3):368-374. https://doi.org/10.1016/j.aogh.2015.08.006

Schilirò T, Alessandria L, Degan R, Traversi D, Gilli G (2010) Chemical characterization and cytotoxic effects in A549 cells of urbanair PM10 collected in Torino. Italy Environ Toxicol Pharmacol 29(2):150-157. https://doi.org/10.1016/j.etap.2009.12.005

Ghanbarian M, Nicknam MH, Mesdaghinia A, Yunesian M, Hassanvand MS, Soleimanifar N et al (2019) Investigation and comparison of in vitro genotoxic potency of PM10 collected in rural and urban sites at Tehran in different metrological conditions and different seasons. Biol Trace Elem Res 189:301-310. https://doi. org/10.1007/s12011-018-1469-9

Mishra R, Krishnamoorthy P, Gangamma S, Raut AA, Kumar H (2020) Particulate matter (PM10) enhances RNA virus infection through modulation of innate immune responses. Environ Pollut 266:115148. https://doi.org/10.1016/j.envpol.2020.115148

Carungo M, Dentali F, Mathieu G, Fontanella A, Mariani J, Bordini $\mathrm{L}$ et al (2018) PM10 exposure is associated with increased hospitalizations for respiratory syncytial virus bronchiolitis among infants in Lombardy. Italy Environ Res 166:452-457. https://doi. org/10.1016/j.envres.2018.06.016

Cruz Sánchez TM, Haddrell AE, Hackett TL, Singhera GK, Marchant D, Lekivetz R et al (2013) Formation of a stable mimic of ambient particulate matter containing viable infectious respiratory syncytial virus and Its dry-deposition directly onto cell cultures. Anal Chem 85(2):898-906. https://doi.org/10.1021/ac302174y

Hirota JA, Marchant DJ, Singhera GK, Moheimani F, Dorscheid DR, Carlsten C et al (2015) Urban particulate matter increases human airway epithelial cell IL-1 $\beta$ secretion following scratch wounding and H1N1 influenza A exposure in vitro. Exp Lung Res 41(6):353-362. https://doi.org/10.3109/01902148.2015. 1040528

Xu Z, Hu W, Williams G, Clements A, Kan H, Tong S (2013) Air pollution, temperature and pediatric influenza in Brisbane. Australia Environ Int 59:384-388. https://doi.org/10.1016/j.envint.2013. 06.022

Zhang R, Meng Y, Song H, Niu R, Wang Y, Li Y et al (2021) The modifications effect of temperature on the relationship between air pollutants and daily incidence on influenza in Ningbo. China Respir Res 22:153. https://doi.org/10.1186/s12931-021-01744-6

Xiao T, Xu H, Xue J, Bai J, Wang Y, Liu Q et al (2019) NF-кBregulation of miR-155, via SOCS1/STAT3, is involved in the PM2.5-accelerated cell cycle and proliferation of human bronchial epithelial cells. Toxicol Appl Pharmacol 377:114616. https://doi. org/10.1016/j.taap.2019.114616

Yang B, Guo J, Xiao C (2018) Effect of PM2.5 environmental pollution on rat lung. Environ Sci Pollut Res Int 25(36):36136-36146. https://doi.org/10.1007/s11356-018-3492-y

Matus P, Oyarzún GM (2019) Impact of Particulate Matter (PM 2.5) and children's hospitalizations for respiratory diseases. A case cross-over study. Rev Chil Pediatr 90(2):166-174. https://doi.org/ 10.32641/rchped.v90i2.750

Ma J-H, Song S-H, Guo M, Zhou J, Liu F, Peng L et al (2017) Longterm exposure to PM2.5 lower influenza virus resistance via down-regulating pulmonary macrophage Kdm6a and mediates histones modification in IL- 6 and IFN- $\beta$ promoter regions. Biochem Biophys Res Commun 493(2):1122-1128. https://doi.org/ 10.1016/j.bbrc.2017.09.013

Rui W, Guan L, Zhang F, Zhang W, Ding W (2016) PM2.5-induced oxidative stress increases adhesion molecules expression in human endothelial cells through the ERK/AKT/NF- $\mathrm{KB}$-dependent pathway. J Appl Toxicol 36(1):48-59. https://doi.org/10.1002/jat.3143

Nimmerjahn F, Dudziak D, Dirmeier U, Hobom G, Riedel A, Schlee M et al (2004) Active NF- $\mathrm{kB}$ signaling is a prerequisite for influenza virus infection. J Gen Virol 85(8):2347-2356. https://doi.org/10. 1099/vir.0.79958-0

Jaligama S, Saravia J, You D, Yadav N, Lee GI, Shrestha B, et al. Regulatory T cells and IL10 suppress pulmonary host defense during early-life exposure to radical containing combustion derived ultrafine particulate matter. Respir Res 2017 18(15). https://doi. org/10.1186/s12931-016-0487-4

Lee GI, Saravia J, You D, Shrestha B, Jaligama S, Hebert VY, et al. Exposure to combustion generated environmentally persistent free radicals enhances the severity of influenza virus infection. Part Fibre Toxicol. 2014;11(57). https://doi.org/10.1186/ s12989-014-0057-1

Liang Y, Fang L, Pan H, Zhang K, Kan H, Brook JR, et al. PM2.5 in Beijing - temporal pattern and its association with influenza. Environ Health. 2014;13(102). https://doi.org/10.1186/ 1476-069X-13-102

Lu B, Wang Y, Zhu Z, Zhang Z, Dong T, Li F et al (2020) Epidemiological and genetic characteristics of influenza virus and the effects of air pollution on laboratory-confirmed influenza cases in Hulunbuir, China, from 2010 to 2019. Epidemiol Infect 148:e159. https://doi.org/10.1017/S0950268820001387

Wrotek A, Badyda A, Czechowski PO, Owczarek T, Dabrowiecki P, Jackowska T (2021) Air pollutants' concentrations are associated with increased number of RSV hospitalizations in polish children. J Clin Med 10(15):3224. https://doi.org/10.3390/jcm10153224

Karr CJ, Rudra CB, Miller KA, Gould TR, Larson T, Sathyanarayana $S$ et al (2009) Infant exposure to fine particulate matter and traffic and risk of hospitalization for RSV bronchiolitis in a region with lower ambient air pollution. Environ Res 109(3):321-327. https:// doi.org/10.1016/j.envres.2008.11.006 
Renwick LC, Brown D, Clouter A, Donaldson K (2004) Increased inflammation and altered macrophage chemotactic responses caused by two ultrafine particle types. Occup Environ Med 61(5):442-447. https://doi.org/10.1136/oem.2003.008227

Pfeffer PE, Ho TR, Mann EH, Kelly FJ, Sehlstedt M, Pourazar J et al (2018) Urban particulate matter stimulation of human dendritic cells enhances priming of naive CD8 T lymphocytes. Immunology 153(4):502-512. https://doi.org/10.1111/imm.12852

Chen Z-H, Wu Y-F, Wang P-L, Wu Y-P, Li Z-Y, Zhao Y et al (2016) Autophagy is essential for ultrafine particle-induced inflammation and mucus hyperproduction in airway epithelium. Autophagy 12(2):297311. https://doi.org/10.1080/15548627.2015.1124224

Chakraborty S, Castranova V, Perez MK, Piedimonte G (2017) Nanoparticles increase human bronchial epithelial cell susceptibility to respiratory syncytial virus infection via nerve growth factorinduced Autophagy. Physiol Rep 5(13):e13344. https://doi.org/ $10.14814 /$ phy2.13344

Lambert AL, Mangum JB, DeLorme MP, Everitt JI (2003) Ultrafine carbon black particles enhance respiratory syncytial virus-induced airway reactivity, pulmonary inflammation, and chemokine expression. Toxicol Sci 72(2):339-346. https://doi.org/10.1093/toxsci/kfg032

Holland HD, Turekian KK. Environmental geochemistry: treatise on geochemistry. 2 ed. United Kingdom: Elsevier; 2005. 9 407-432

Sunil VR, Vayas KN, Massa CB, Gow AJ, Laskin JD, Laskin DL (2013) Ozone-induced injury and oxidative stress in the bronchiolar epithelium are associated with altered pulmonary mechanics. Toxicol Sci 133(2):309-319. https://doi.org/10.1093/toxsci/kft071

Holze C, Michaudel C, Mackowiak C, Haas DA, Benda C, Hubel P et al (2018) Oxeiptosis, a ROS-induced caspase-independent apoptosis-like cell-death pathway. Nat Immunol 19(2):130-140. https://doi.org/10.1038/s41590-017-0013-y

Kesic MJ, Meyer M, Bauer R, Jaspers I (2012) Exposure to ozone modulates human airway protease/antiprotease balance contributing to increased influenza A infection. PLoS ONE 7(4):e35108. https://doi.org/10.1371/journal.pone.0035108

Wong CM, Yang L, Thach TQ, Chau PYK, Chan KP, Thomas GN et al (2009) Modification by influenza on health effects of air pollution in Hong Kong. Environ Health Perspect 117(2):248-253. https:// doi.org/10.1289/ehp.11605

Meng Y, Lu Y, Xiang H, Liu S (2021) Short-term effects of ambient air pollution on the incidence of influenza in Wuhan, China: a time-series analysis. Environ Res 192:110327. https://doi.org/10. 1016/j.envres.2020.110327

Ali ST, Wu P, Cauchemez S, He D, Fang VJ, Cowling BJ et al (2018) Ambient ozone and influenza transmissibility in Hong Kong. Eur Respir J 51(5):1800369. https://doi.org/10.1183/13993003. 00369-2018

Ji JH, Na C, Qiang SZ, Jing YIN, Gang QZ, Jing M et al (2019) Inactivation of poliovirus by ozone and the impact of ozone on the viral genome. Biomed Environ Sci 32(5):324-333. https://doi.org/10. 3967/bes2019.044

Lin Y-C, Juan H-C, Cheng Y-C (2007) Ozone exposure in the culture medium inhibits enterovirus 71 virus replication and modulates cytokine production in rhabdomyosarcoma cells. Antiviral Res 76(3):241-251. https://doi.org/10.1016/j.antiviral.2007.07.004

Carazo Fernández L, Fernández Alvarez R, González-Barcala FJ, Rodríguez Portal JA (2013) Indoor air contaminants and their impact on respiratory pathologies. Arch Bronconeumol 49(1):22-27. https://doi.org/10.1016/j.arbr.2012.11.004

Gordon SB, Bruce NG, Grigg J, Hibberd PL, Kurmi OP, Kin-bong HL et al (2014) Respiratory risks from household air pollution in low and middle-income countries. Lancet Respir Med 2(10):823-860. https://doi.org/10.1016/S2213-2600(14)70168-7
Nsoh M, Mankollo BOY, Ebongue M, Cyprien KN, Likeng JLN, Islam SMS et al (2019) Acute respiratory infection related to air pollution in Bamenda, North West Region of Cameroon. Pan Afr Med J 32:99. https://doi.org/10.11604/pamj.2019.32.99.15228

Foster S, Bedford KJ, Gould MEL, Coward WR, Hewitt CRA (2003) Respiratory syncytial virus infection and virus-induced inflammation are modified by contaminants of indoor air. Immunology 108(1):109-115. https://doi.org/10.1046/j.1365-2567.2003. 01539.x

Hallak LK, Spillmann D, Collins PL, Peeples ME (2000) Glycosaminoglycan sulfation requirements for respiratory syncytial virus infection. J Virol 74(22):10508-10513. https://doi.org/10.1128/ jvi.74.22.10508-10513.2000

Ghaemmaghami AM, Robins A, Gough L, Sewell HF, Shakib F (2001) Human $\mathrm{T}$ cell subset commitment determined by the intrinsic property of antigen: the proteolytic activity of the major mite allergen Der $\mathrm{p} 1$ conditions T cells to produce more IL-4 and fewer IFN- $\gamma$. Eur J Immunol 31(4):1211-1216. https://doi.org/10.1002/ 1521-4141(200104)31:4\%3c1211::AID-IMMU1211\%3e3.0.CO;2-R

Comoy EE, Pestel J, Duez C, Stewart GA, Vendeville C, Fournier C et al (1998) The house dust mite allergen, Dermatophagoides pteronyssinus, promotes type 2 responses by modulating the balance between IL-4 and IFN- $\gamma$. J Immunol 160(5):2456-2462

Maedel C, Kainz K, Frischer T, Reinweber M, Zacharasiewicz A (2018) Increased severity of respiratory syncytial virus airway infection due to passive smoke exposure. Pediatr Pulmonol 53(9):1299-1306. https://doi.org/10.1002/ppul.24137

Groskreutz DJ, Monick MM, Babor EC, Nyunoya T, Varga SM, Look DC et al (2009) Cigarette smoke alters respiratory syncytial virusinduced apoptosis and replication. Am J Respir Cell Mol Biol 41(2):189-198. https://doi.org/10.1165/rcmb.2008-0131OC

Castro S, Chakraborty K, Guerrero- PA (2011) Cigarette smoke suppresses TLR-7 stimulation in response to virus infection in plasmacytoid dendritic cells. Toxicol in Vitro 25(5):1106-1113. https://doi.org/10.1016/j.tiv.2011.03.011

Poon J, Campos M, Foronjy RF, Nath S, Gupta G, Railwah C et al (2019) Cigarette smoke exposure reduces leukemia inhibitory factor levels during respiratory syncytial viral infection. Int J Chron Obstruct Pulmon Dis 14:1305-1315. https://doi.org/10.2147/ COPD.S196658

Modestou MA, Manzel LJ, El-Mahdy S, Look DC. Inhibition of IFN- $\gamma$-dependent antiviral airway epithelial defense by cigarette smoke. Respir Res. 2010; 11(64). https://doi.org/10.1186/ 1465-9921-11-64

Yang W, Elankumaran S, Marr LC (2011) Concentrations and size distributions of airborne influenza A viruses measured indoors at a health center, a daycare center, and on airplanes. J R Soc Interface 8(61):1176-1184. https://doi.org/10.1098/rsif.2010.0686

Feng Y, Kong Y, Barnes PF, Huang F-F, Klucar P, Wang X et al (2011) exposure to cigarette smoke inhibits the pulmonary T-cell response to influenza virus and Mycobacterium tuberculosis. Infect Immun 79(1):229-237. https://doi.org/10.1128/IAI.00709-10

Zhou Y, Kang M-J, Jha BK, Silverman RH, Lee CG, Elias JA (2013) Role of RNase L in viral PAMP/influenza virus and cigarette smoke-induced inflammation and remodeling. J Immunol 191(5):2637-2646. https://doi.org/10.4049/jimmunol.1300082

Wang J, Li Q, Xie J, Xu Y. Cigarette smoke inhibits BAFF expression and mucosal immunoglobulin A responses in the lung during influenza virus infection. Respir Res. 2015 16(37). https://doi.org/ 10.1186/s12931-015-0201-y

Publisher's note Springer Nature remains neutral with regard to jurisdictional claims in published maps and institutional affiliations. 